\title{
Making Decisions in Planning and Risk Management System of Enterprise in Project Management
}

\author{
Anatolii Zhigir* \\ Peter the Great St. Petersburg Polytechnic University, 29 Politekhnicheskaya Street, St. Petersburg, \\ 195251, Russia
}

\begin{abstract}
The purpose of this article is to scientifically and methodically substantiate and improve the mechanism for making effective management decisions in the implementation of investment projects of an enterprise within the time period set by the investor, taking into account risk and uncertainty. The article deals with the theoretical foundations of the construction of a model for the implementation of investment projects, taking into account risk and uncertainty as well as the methodology for the management of investment projects, taking into account the technology and organization of work. The work focuses on the improvement of the mechanism for the effective use of investment resources at the enterprise through the introduction of project management methods and the development of the best option for determining an effective solution for the implementation of the project within the established deadline, taking into account risk factors and uncertainty. The conducted analysis made it possible to conclude that the use of network modeling methods to the fullest extent possible corresponds to the task of project management, performance of work in interconnection and dynamics in the investment sphere. An improved system for the management of investment projects leads to the creation of an optimal mechanism for using investments at an enterprise, allows solving the problem of completing a project at a set date, as well as increasing the validity of decisions made in the management of investment projects of enterprises.
\end{abstract}

\section{Introduction}

The current level of production development requires fundamental changes in management methods and the widespread introduction of complex automation of production processes as well as the adoption of optimal decisions. Yet, the difficulties are obvious, since any organization represents a system consisting of a significant number of interconnected elements that function as a whole, transforming resources into products.

"Project Management (PM) is the art of leadership and coordination of human and material resources throughout the life cycle of a project by applying modern methods and

\footnotetext{
*Corresponding author: azhigir@gmail.com
} 
techniques of management to achieve the results defined in the project in terms of the scope of works, cost, time, quality and satisfaction of the project participants."

\section{Main part}

Initiation and planning to achieve the goals of an investment project is the most important stage. Functional goals can be subdivided into technical, organizational, social and economic ones.

Describing the decision-making process in project management, it should be noted that

- recently, the amount of information required for making balanced decisions has sharply increased;

- the time for making decisions has been reduced;

- the losses due to the untimely and erroneous decisions made have increased;

- the number of criteria and factors that determine the choice of the best solution has increased.

One of the first methods of project management includes the rational and simple method of describing a project with the help of a computing machine, created in 1956 by M. Walker and D. Kelly. It was originally called the Walker-Kelly method, and later it was renamed in the Critical Path Method (or CPM). Alongside this, the US Navy developed independently the PERT (Program Evaluation and Review Technique) method to analyze and assess programs. [1] The formation of homegrown project management methodology coincided with the first publications on network methods in the early 1960s. - G.S. Pospelov, A.I. Teiman (1963), Yu.A. Avdeyev (1963), S.I. Zukhovitskiy, N.A. Radchik, and many others.

Backed up by our own developments, in the 1970s, methods of network modeling achieved the widespread acceptance. By 1975, the number of enterprises using network modeling methods amounted to about $18 \%$ of the total.

Based on the network models, it is possible to present the entire production process, from the inception of a project idea to its implementation, in a single model in interconnection, as well as to carry out its information description that meets the established selection criteria and rules, and to search for the most effective option. [2] An important difference between network models and Gantt charts and timing diagrams is that, if it is necessary to adjust the timing of work, network models allow you to study the duration of the investment project without changing the topological structure of the graph, by changing the early start and end dates of work, as well as the float time for their implementation.

Further development of network models are random models with random values of the duration of work and a determined network. The listed network models had become the basis on which network planning and management systems (NMS) were developed and implemented in many sectors of the national economy, which subsequently played an important role in the creation and development of automated enterprise control systems.

In production, simulation methods are used to display and study various organizational and technological processes with minimal costs for the preparation of relevant information and bringing research to its end.

Simulation methods make it possible to solve issues of enforcement of the efficient performance of work, taking into account the actual availability of material resources, restrictions on labor and technical resources, existence of a scope of works and other problems related to resources. They also allow taking into account periodically observed situations concerning the overrun or violation of construction time standards.

Reliability is ensured by the reservation of material, technical, labor and financial resources, on which the results of the project depend. The concept of reliability is associated with the theory of probability and mathematical statistics. The existing theory of 
reliability, its mathematical and computational tools correspond largely to the conditions for the functioning of technical systems and give no satisfactory result in the field of production management. [3]

Today, it is possible to perform the assessment of uncertainties and uncertainty management using various methods. To a considerable degree, assessments of the level of risk of decision-making or assessments of the probability of bankruptcy of an enterprise are used.

An example of a classical approach to assess the financial condition of an enterprise is the method of credit scoring developed by D. Durand, an American economist, in the early forties of the last century.

The Durand model calculates a complex indicator of the financial condition in the form of the solvability of an enterprise. The value of each indicator is assigned with a certain score, the value of which is calculated according to linear interpolation within each class. The complex indicator is calculated as the sum of scores for all indicators of the financial condition of the enterprise, the qualitative gradation of which is presented in the form of the distribution of enterprises by their classes, in accordance with the rating number - the sum of scores. Nowadays, there are many models of credit scoring in use - where the emphasis is made on those points that the authors considered more important.

Economic and mathematical modeling is used as a way to assess and predict the financial activities of an enterprise at the formal level. All the models can be divided into three main groups - statistical models, artificial intelligence models, and theoretical models. $[4,5]$

Statistical models are the most widely represented in assessing the verging of bankruptcy of enterprises. They have the following features:

- they emphasize and focus on possible (alleged) signs of bankruptcy;

- they take all information from financial and accounting statements;

- classical statistical modeling capabilities are used when calculating.

Within the scope of the statistical approach, the following modeling methods can be distinguished:

1) discriminant analysis;

2) analysis of conditional probability;

3) cluster analysis;

4) survival analysis;

5) binary choice.

In world and domestic practice, among the statistical models, the models based on discriminant analysis are most widely used. This approach consists in analyzing the ratio of financial coefficients, constructing a discriminant function using mathematical and statistical procedures and calculating the integral indicator $\mathrm{Z}$, on the basis of which, with a certain degree of probability, the bankruptcy of a business entity can be predicted.

The most famous models for assessing the probability of bankruptcy of enterprises, obtained using discriminant analysis, are the models of such well-known Western economists as E. Altman (1968), G. Springate (1978) and others.

Artificial intelligence models are of our particular note.

The special features of these models are as follows:

- they focus on possible symptoms of bankruptcy;

- all information is taken from the financial statements of the enterprise;

- they can be multidimensional;

- they depend on computer power and technology.

Within the scope of artificial intelligence, the following modeling methods can be distinguished:

1) decision tree; 
2) neural networks;

3) expert systems;

4) fuzzy-set theory;

5) genetic algorithms;

6) support vector machine.

The advantage of artificial intelligence models is that, compared to statistical models, they can show a good calculation result when working with incomplete and inaccurate data.

Today, no forecasting method can do without the use of various mathematical theories. They can be divided into quantitative and qualitative.

Quantitative methods are based on information that can be obtained by knowing the trend of changes in parameters or having statistical data characterizing the production activity of the controlled object. Qualitative methods are based on expert assessments of specialists in the field of decisions made. Widely used forecasting methods are also methods such as the "brainstorming" method, the Delphi method, extrapolation of the investigated trends, etc. [6]

Methods of expert assessments have become very popular. Almost $25 \%$ of economic decisions are made intuitively, therefore, analytical methods of expert assessments are increasingly used. These methods are based on the use of professional experience and intuition of a specialist in solving analytical problems, especially when predicting the development of economic situations. [7]

The study of scientific and methodological approaches allows us to come to the conclusion about the existing practice of separating methods of analysis from methods of reducing the risk of an investment project, which is not permissible for its systematic consideration. Thus, most authors distinguish revealing risk (risk identification) and risk assessment as separate stages of the management process, but it is the identification and ranking of risks that is the first stage of the assessment. Therefore, these stages cannot be considered as separate ones.

In our opinion, the risk and its level will be determined by the implementation stage of the investment and construction project, which has time limits. This takes place because the situation, as it is developing, changes the level of risk, increasing or decreasing it under the influence of new, additional risk factors.

This, in turn, can change the degree of managerial influence. With the help of risk assessment methods at each stage of an investment and construction project, it is necessary to determine the level of risk and attract appropriate methods to reduce it, control it, with the aim of promoting a reliable and successful implementation of an investment and construction project. [8]

Therefore, such stages as risk assessment and risk management cannot be carried out sequentially, and should be applied in parallel when involving.

Having analyzed all the mentioned approaches to define the components of the risk management process, it is possible to reduce them to certain stages.

At the first stage, the identification and selection of investment goals is carried out, which implies the identification of an attitude to risk (in terms of making decisions about the appropriateness of a particular risk level), and a strategy for attracting the necessary assessment methods to obtain results exactly as expected.

Investment objectives of risk, liquidity and profitability will characterize the reliability of the project and its compliance with a specific purpose of its implementation. That is, the risk, its level, as well as the strategy of risk management will depend on other investment characteristics, which actually will ensure the reliability of the project.

The second stage involves such complex actions as risk assessment, analysis of the external environment, selection of a risk management strategy; determination of appropriate 
risk management methods, their involvement; assessment of the results of risk management.

When developing a risk management strategy, attention should be paid to the factors in which the safety margin is the lowest one. At the same time, one should not ignore other factors influencing the results of the investment project. [9, 10]

Depending on the chosen strategy, further activities of the construction company are planned, taking into account the impact of exogenous and endogenous factors. They will help to objectively identify risks, assess them and make an effective management decision.

Generalized economic practice shows that the assessment of the results of risk management should be carried out after engaging each of the methods (techniques) of management, that is, to assess risk management not at the last stage of project implementation, but even at the development stages, which in turn will make it possible to influence future decisions on the project, support it or abandon the project as a whole or some of its individual components. With this approach to risk management, the costs at the initial stages are still minimal and it is quite easy to make changes to the project.

After the choice of measures to minimize and completely eliminate the risk takes place, a decision should be made about the degree of their sufficiency. If the measures are not enough, it is advisable to abandon the project to minimize the risk.

The complex of actions "assessment - management - result" must be carried out as a part of the project analysis several times (cycles), and on the last of them, when all possible management techniques have been exhausted, we will have a project (model of its implementation) with the maximum chances of being successfully implemented.

It should be noted that the existing methods to assess the effectiveness and risks of an investment project are based on the result of identifying the very fact of the project's riskiness and establishing the predicted future income, subject to the acceptance of certain data.

At the same time, the approach to risk management, when a multiple set of actions is assumed to assess the effectiveness of risk management, is not so much focused on the fact of riskiness as the purpose of the study, but on achieving the maximum result from the project (the best investment characteristics), and gives certain specific recommendations for its implementation.

There is a link between a risk mitigation strategy and how it is managed because each strategy has its own set of implementation tools. Therefore, when making decisions on project design, risk management methods in general should be taken into account. Management provides for the influence of the subject on the object with the provision of feedback.

In turn, influence as a general concept includes both mitigation and neutralization, prevention, etc. Therefore, it would be correct to define the risk response system precisely through the concept of risk management.

Risk management methods, when moving from one stage to another, change significantly, because the risk management process is continuous and responsible throughout the entire project cycle in general.

It should be noted that as all methods have their pros and cons, the use of several methods in combination will more effectively prevent the emergence of a new risk and ensure the reliability of projects against the impact of existing risks.

Risk management strategies are in line with the corresponding stages of the implementation of investment and construction projects.

Thus, at the stage of pre-project grounds, the following items are applied - the "risk avoidance (prevention)" strategy, as well as the methods that form the direction of risk mitigation, which allow taking into account the risks at the early stages and avoiding them, if possible. In turn, this will reduce the possibility of project failure even before contract 
conclusion and, actually, construction. The most effective ones are the methods of the "risk prevention" strategy - strategic planning, forecasting the development of the internal and external environment, constant collection and processing of information concerning the state of the causes of risk.

The project development stage contains a risk-taking risk management strategy, one of the main methods of which is funds reservation. It is at this stage that the development of a specific project takes place and the investor must determine the level of risk that must be taken during this stage.

The third stage includes a "transfer or distribution of risk" strategy. This distribution is due to the fact that during this stage, third-party organizations are involved in risk management and contracting. This is just possible during the implementation and operation of the project, when the investor has already assumed exactly that part of the risk he expected and which he is able to keep control of, the other risks should be transferred to insurance organizations, suppliers, banks, etc. The use of an effective organizational and economic mechanism in the project requires additional costs from the participants, which are subject to mandatory optimization.

Risk management methods, when moving from one stage to another, change significantly, because the risk management process is continuous and responsible throughout the entire project cycle in general.

When choosing a risk management toolkit for a construction company, you need to pay attention to the peculiarities of applying risk management methods in relation to each of the stages of the project and, no less important, to the advantages and disadvantages of each of the methods, applying them in combination.

\section{Conclusions}

After analyzing the principles that are laid down in the risk management strategy, it is possible to conclude that the continuous, multi-cyclical risk management process, which is designed to continuously identify risks, induce the development of effective mechanisms for managing them, their implementation and subsequent assessment of the effectiveness of the measures taken, is fully integrated into the basis of the principles of implementation of anti-crisis management. Risk management processes are an integral part of anti-crisis management, taking into account the unidirectional nature of their goals, the affinity of the subject-object composition of these processes.

When applying these techniques, both positive and negative properties should be noted. As a result of the analysis, it should be noted that their use is difficult, and in some cases even impossible because of the following reasons:

- little attention has been paid to the development of methods for solving the problem of completing projects in the prescribed time, the efficiency of the study of the duration when changing the defining initial data that affect the duration of the project;

- the methods used to take into account risk and uncertainty when determining the reliability of project execution do not take into account the influence of the "time-cost" relationship, random characteristics of individual works, which ultimately can significantly affect the real terms of work and is very important when moving to a strict contractual relationship between investor and contractor;

- the methodology for determining the economic efficiency from the reduction of the terms of implementation of investment projects is not clearly developed.

The conducted analysis made it possible to conclude that the use of network modeling methods most fully corresponds to the task of project management, performance of work in interconnection and dynamics in the investment sphere. 


\section{References}

1. Chizhikova E.S. Komandoobrazovaniye [Team Building]. Tyumen, TyumGNGU Publ., 2011, 117 p.

2. Jin Yujiao. An approach to ensuring the efficiency of investment projects in the context of network structures. Materialy Vserossiyskoy nauchno-prakticheskoy konferentsii: Tsifrovaya ekonomika: tekhnologii, upravleniye, chelovecheskiy capital [Materials of the All-Russian Scientific and Practical Conference: Digital Economy: Technologies, Management, Human Capital]. Moscow State Technological University STANKIN Publ., 2019, pp. 121-128.

3. Diekman L.G. Organizatsiya stroitelnogo proizvodstva [Organization of construction production]. Association of Construction Universities Publ., M., 2006, 607 p.

4. Zhigir A.A. Calculation of the economic effect of environmental measures. IOP Conference Series: Earth and Environmental Science. Conference proceedings. Krasnoyarsk Science and Technology City Hall of the Russian Union of Scientific and Engineering Associations. C. 72002. DOI: 10.1088/1755-1315/421/7/072002, (2020)

5. Zhigir A. A. Methodology for evaluating effectiveness and forecast of the digital economy projects. Proceedings of the International Scientific and Practical Conference on Digital Economy (ISCDE 2019) (2019) DOI: 10.2991/iscde-19.2019.55

6. Alkdirou Radvan Khalid, Mylnikov L.A. Algorithm for constructing forecasts of parameters of innovative projects, taking into account their mutual influence on each other. Management of economic systems: electronic scientific journal, 2012, No. 8. p. 3.

7. Pitolin M.V., Preobrazhenskiy Y.P. Management of distributed energy systems on basis of optimization methods and expert approaches. Modeling, optimization and information technology. No. 1, pp. 34-35. (2020) DOI: 10.26102/2310$6018 / 2020.28 .1 .031$

8. Muratova A., Ptukhina I. Bim as an instrument of a conceptual project cost estimation. Lecture Notes in Civil Engineering, 2020, No. 70, 469-77.

9. Litvinenko I.L, Sokolova E.M., Kriklivaya M.G., Li A.S., Kiyanova L.D. Evolution of project management in commercial institutions. Journal of Advanced Research in Dynamical and Control Systems, 2019, No. 1: 511-18.

10. Dubrovina N.A., Gorelova N.Y. Innovative development of mechanical engineering complex based on project management. IOP Conference Series: Earth and Environmental Science International Science and Technology Conference 'EarthScience': Institute of Physics Publ., 2020, P. 062067. 